JEEP 2011, 00006 (2011)

DOI: $10.1051 /$ jeep/201100006

(C) Owned by the authors, published by EDP Sciences, 2011

\title{
Binary phase diagram between phenanthrene and its main impurity: dibenzothiophene
}

\author{
N. Couvrat, Y. Cartigny, S. Tisse, M-N. Petit, G. Coquerel \\ Laboratoire SMS - EA 3233, IMR4114 - Université de Rouen-76821 Mont Saint Aignan Cedex, France
}

\begin{abstract}
The binary phase diagram between commercial Phenanthrene and its main impurity, Dibenzothiophene, is established under atmospheric pressure by means of structural and thermal analyses. This determination appears as a requirement for performing efficient zone melting on Phenanthrene. The investigations on this binary phase diagram reveal stable and metastable eutectic invariants and a single eutectoid invariant. Two hypotheses are proposed for an undetermined invariant detected at $80^{\circ} \mathrm{C}$ in the domain rich in Dibenzothiophene. Moreover, solid-solutions in the Phenanthrene rich-domain are characterized. Finally, the impact of these heterogeneous equilibria on the feasibility of Phenanthrene refining by means of zone melting is discussed.
\end{abstract}

\section{Introduction}

In the field of organic materials, and more particularly of Active Pharmaceutical Ingredients (APIs), the chemical and structural purities are critical in the development of an API [1]. Melt crystallization [2], especially the zone melting technique, is sometime used to access to very high pure materials or even 'ultra-pure' (purity greater than $99.9 \%$ ). This technique is used as a routine in metallurgy [3], but is still seldom applied to organic compounds, due to recurrent degradation problems upon melting. Nevertheless, a laboratory device was recently successful to separate impurities from organic ionic liquids [4]. In order to reach high purities on APIs studied in the laboratory, a new zone melting apparatus was built.

Phenanthrene (figure 1) was chosen to test the prototype because it exhibits a good stability above its melting point, and was already studied by zone melting [6].<smiles>c1ccc2ccccc2c1</smiles>

Fig. 1. Developed formula of the Phenanthrene molecule $\left(\mathrm{Mp} \sim 101^{\circ} \mathrm{C}\right)$

In this work, the classical procedure used to purify a given molecule by zone melting was applied. After identifying the impurities contained in the starting batch, the binary phase diagram between Phenanthrene and its main impurity (Dibenzothiophene) was experimentally determined.

\section{State of the art}

Phenanthrene belongs to the polycyclic aromatic hydrocarbon group (Figure 1), and exhibits a solid-solid transition from a low temperature form (LT hereafter, monoclinic $\mathrm{P} 2_{1}$ ) to a high temperature disordered form (HT hereafter, monoclinic $\mathrm{P} 2{ }_{1} / \mathrm{a}$ ) at circa $71^{\circ} \mathrm{C}$ [5].

This transition can be observed by Temperature Resolved X-Ray diffraction: two specific peaks disappear between $70^{\circ} \mathrm{C}$ and $80^{\circ} \mathrm{C}$ together with signs of lattice expansion (Figure 2).

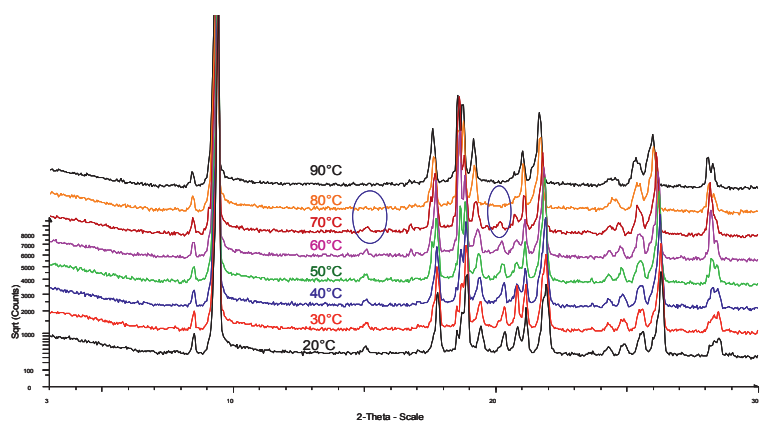

Fig. 2. Temperature controlled X-Ray powder diffraction performed on commercial Phenanthrene (98\% pure). The transition is characterized by the blue circles

As a coal tar residue [7], commercial Phenanthrene contains a lot of impurities (mainly other fused-ring derivatives). These latter were detected by gas 
chromatography coupled to mass spectrum analysis (Table 1).

Table 1. Main impurities of commercial Phenanthrene determined by GC-MS analysis: dibenzothiophene (a), fluorene (b), carbazole (c) and anthracene (d)

\begin{tabular}{|c|c|c|c|}
\hline $\begin{array}{c}\mathrm{Mp} \sim 100^{\circ} \mathrm{C} \\
1.3 \% \text { in the } \\
\text { sample }\end{array}$ & $\begin{array}{c}\mathrm{Mp} \sim 117^{\circ} \mathrm{C} \\
0.6 \% \text { in the } \\
\text { sample }\end{array}$ & $\begin{array}{c}\mathrm{Mp} \sim 246^{\circ} \mathrm{C} \\
\text { undefined }\end{array}$ & $\begin{array}{c}\mathrm{Mp} \sim 218^{\circ} \mathrm{C} \\
0.4 \% \text { in the } \\
\text { sample }\end{array}$ \\
\hline a) & b) & c) & d) \\
\hline
\end{tabular}

Among the numerous impurities distributed in the commercial sample, Dibenzothiophene appeared as the major one (more than twice concentrated than the second impurity, i.e. Fluorene).

So far, the binary phase diagram between Phenanthrene and its main impurity (at atmospheric pressure) has not been the subject of any study. It was thus the goal of the present work by means of structural and thermal analyses. Even though the only part of interest in the diagram is the Phenanthrene rich side (for zone melting purification), all the composition range was explored.

\section{Materials and Methods}

\subsection{Materials}

Commercial Phenanthrene and Dibenzothiophene supplied by Alfa Aesar, were both $98 \%$ pure. The products were used without any further purification.

\subsection{X-Ray Powder Diffraction}

XRPD analyses (at ambient temperature) were performed on a D5000 matic diffractometer (Bruker).

Temperature resolved XRPD analyses were performed on a D5005 Siemens.

All XRPD data were processed by using EVA 12 software (Bruker).

\subsection{Thermal analyses (DSC)}

Differential scanning calorimetry (DSC) analyses were performed on a DSC NETZSCH 204 F1 equipped with an intra-cooler. Samples were put in a 301 aluminium crucible and heated at a rate $5 \mathrm{~K} / \mathrm{min}$. He was used as purging gas.

\section{Results and discussion}

\subsection{Preparation of the samples}

Prior DSC analysis, every binary mixture of Phenanthrene/ Dibenzothiophene (1g of total mass) was fully dissolved with $2 \mathrm{~mL}$ of acetone in vials, evaporated and manually ground.

\subsection{X-Ray Powder diffraction}

Structural analyses (XRPD) on binary mixtures were performed at ambient temperature $\left(\sim 25^{\circ} \mathrm{C}\right)$ (Figure 3 ).

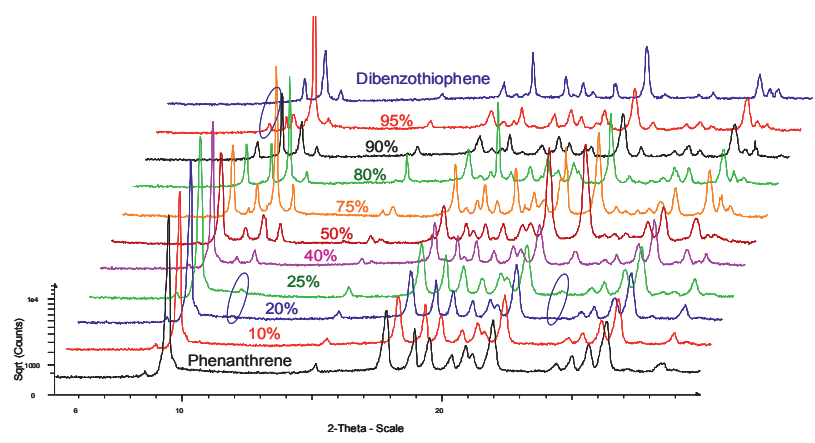

Fig. 3. Perspective view of XRPD analyses performed at $25^{\circ} \mathrm{C}$ with mixtures going from Phenanthrene to Dibenzothiophene

(in mass $\%$ of Dibenzothiophene). Blue circles display the domain transitions characteristics

From "pure" Phenanthrene to $20 \%$ of Dibenzothiophene, a solid solution of Phenanthrene LT is only observed. Above 25\%, there is a biphasic solid domain (solid solution of Phenanthrene LT + Dibenzothiophene).

\subsection{Thermal analyses}

Binary mixtures were analyzed by DSC ( $5 \mathrm{~K} / \mathrm{min})$ up to $110^{\circ} \mathrm{C}$ in sealed sample pans. Two successive heating ramps were applied to every sample.

A recurrent problem encountered was the tendency of Phenanthrene to sublimate under heating. Then, the first heating ramp should be more reliable than the second even if the dead volumes over the solid samples were minimized. For the same reason, XRPD at variable temperature can thus not be conclusive for this system. The phenomena recorded by DSC analyses are compiled in Figure 4.

According to the presence of two polymorphic forms for Phenanthrene and the XRPD collected on binary mixtures at ambient temperature, thermal events obtained during DSC measurements can be interpreted.

Several invariants were characterized in this system (Table 2).

The temperature of the polymorphic transition of Phenanthrene slightly decreases when Dibenzothiophene content increases and then it seems to reach a eutectoid invariant at circa $63^{\circ} \mathrm{C}$. The invariant recorded at $68^{\circ} \mathrm{C}$ should probably belong to a metastable eutectic (invariant 3 Figure 4). Indeed, this thermal event disappears during the second heating ramp or if a DSC measurement is carried out after a 4 hours annealing at $65^{\circ} \mathrm{C}$. Finally, the stable eutectic invariant, consistent with solidus and liquidus curves, is located at circa $73^{\circ} \mathrm{C}$ (invariant 2, Figure 4). 


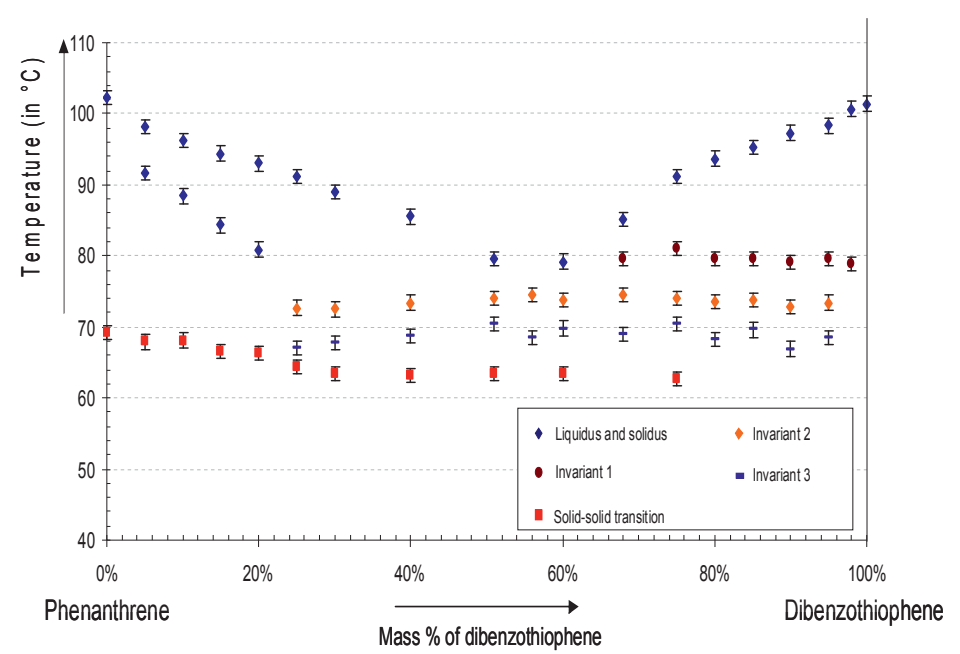

Fig. 4. Compilation of experimental thermal phenomena (DSC) between Phenanthrene and Dibenzothiophene

Table 2. Details of invariant equilibria identified by thermal analyses in the Phenanthrene/Dibenzothiophene phase diagram (compositions in \%wt of Dibenzothiophene)

\begin{tabular}{|c|c|c|c|c|}
\hline Temperature & Type & \multicolumn{3}{|c|}{ Phases involved in equilibrium } \\
\hline $63^{\circ} \mathrm{C}$ & Eutectoid & $\begin{array}{c}\text { Solid solution of } \\
\text { Phenanthrene LT }(21 \% \mathrm{wt})\end{array}$ & $\begin{array}{c}\text { Solid solution of } \\
\text { Phenanthrene HT }(\sim 22 \% \mathrm{wt})\end{array}$ & Dibenzothiophene $_{\text {solid }}$ \\
\hline $68^{\circ} \mathrm{C}$ & $\begin{array}{c}\text { Eutectic } \\
(\text { metastable })\end{array}$ & $\begin{array}{c}\text { Solid solution of } \\
\text { Phenanthrene LT }(\sim 23 \% \mathrm{wt})\end{array}$ & $\begin{array}{c}\text { Liquid } \\
(\sim 58 \% \mathrm{wt})\end{array}$ & Dibenzothiophene $_{\text {solid }}$ \\
\hline $73^{\circ} \mathrm{C}$ & Eutectic & $\begin{array}{c}\text { Solid solution of } \\
\text { Phenanthrene HT }(\sim 23 \% \mathrm{wt})\end{array}$ & $\begin{array}{c}\text { Liquid } \\
(\sim 58 \% \mathrm{wt})\end{array}$ & Dibenzothiophene $_{\text {solid }}$ \\
\hline $80^{\circ} \mathrm{C}$ & Unknown & - & - & - \\
\hline
\end{tabular}

Another invariant transformation was determined in the rich Dibenzothiophene part at circa $80^{\circ} \mathrm{C}$ (invariant 1 , Figure 4). This invariant could not be characterized (even by means of TR-XRPD), but several hypotheses can be proposed to explain its nature:

1) This is a peritectic transformation : $<$ Dibenzothiophene low temperature form $>\vec{*}$ liquid $+<$ Dibenzothiophene high temperature form $>$. This case is depicted in Figure 6. It implies that Dibenzothiophene presents two polymorphic forms with a sub-ambient transition temperature. Moreover, this two forms lead to a solid solution with Phenanthrene in a very small concentration range. This case would be remarkable as it should induce an increasing of the polymorphic transition temperature from at least $80^{\circ} \mathrm{C}$ [8].

2) This a solid-solid transition of the Dibenzothiophene which is not disturbed by the presence of Phenanthrene. Nevertheless, no polymorph of Dibenzothiophene was reported so far.

\subsection{Experimental binary phase diagram}

By combination of structural (XRPD at ambient temperature) and thermal (DSC) analyses performed on the overall range of composition between Phenanthrene and Dibenzothiophene, a binary phase diagram (under atmospheric pressure) displaying the stable equilibria could be proposed (Figure 5).

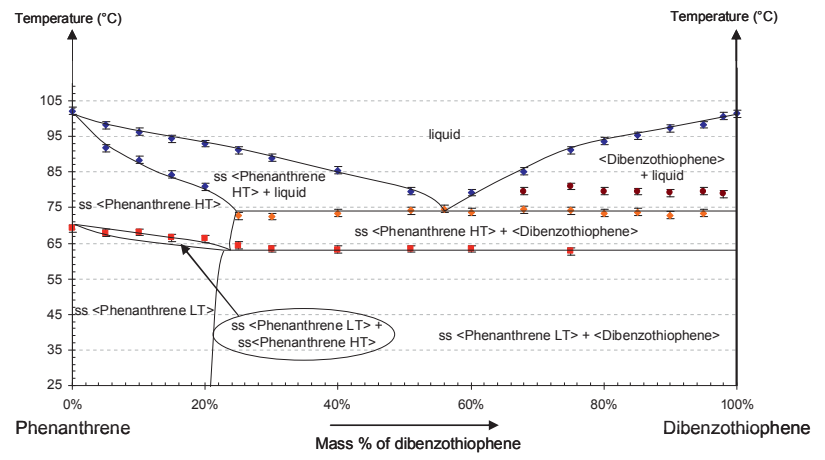

Fig. 5. Proposal for a binary phase diagram Phenanthrene/ Dibenzothiophene. The invariant at circa $80^{\circ} \mathrm{C}$ is not interpreted in this proposal

\subsection{Discussion}

The diagram presented in Figure 5 is incomplete, more particularly in the region rich in Dibenzothiophene, because the last invariant at circa $80^{\circ} \mathrm{C}$ was not characterized. The first hypothesis proposed above seems to be the more consistent with current experimental data. Figure 6 displays the complete phase diagram involving a peritectic invariant. 


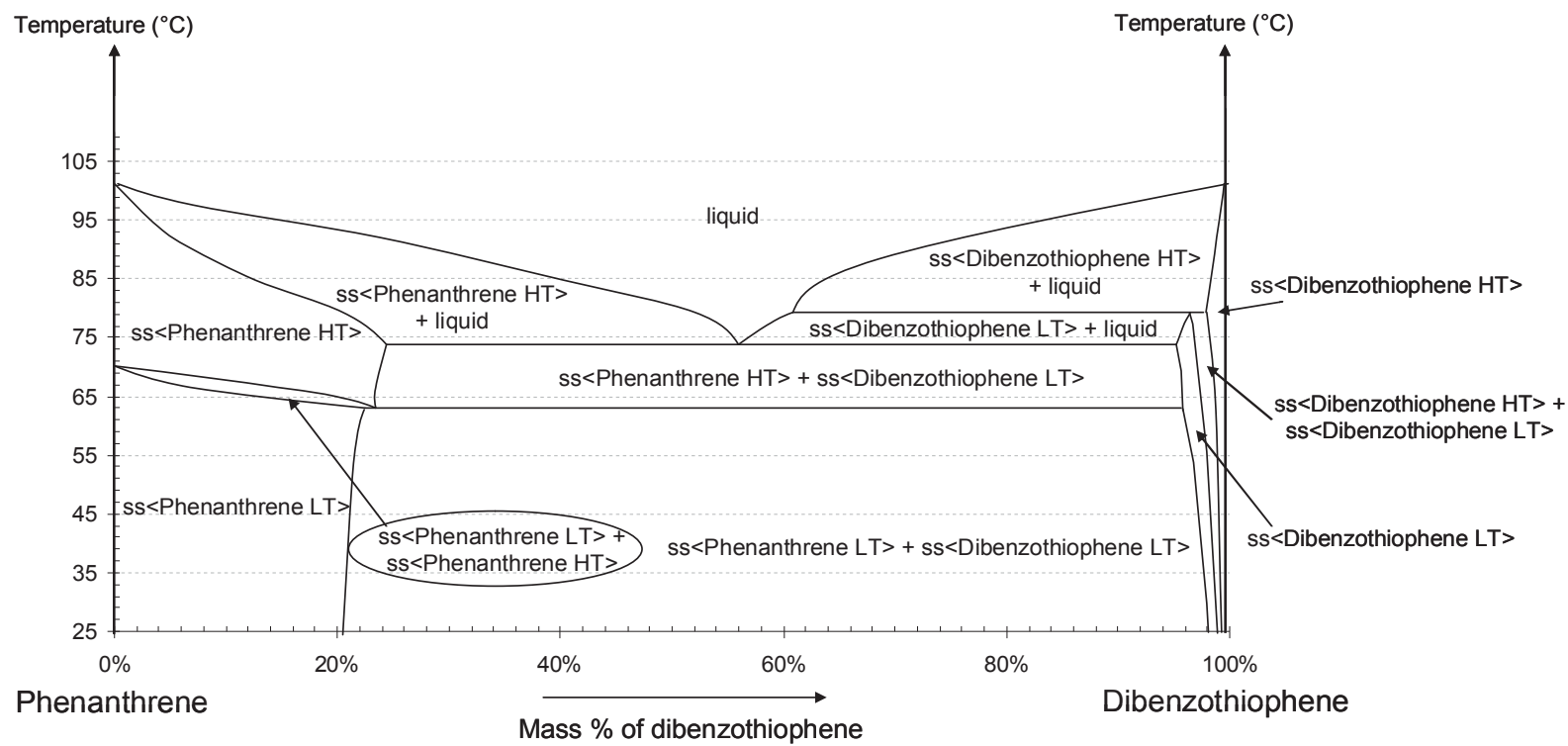

Fig. 6. Proposal for a binary phase diagram Phenanthrene/ Dibenzothiophene implying the presence of two Dibenzothiophene polymorphs

Even if this binary phase diagram is not fully characterized, it gives important indications on the impact of Dibenzothiophene (as an impurity) on the solid behaviour of Phenanthrene. Indeed, for the purpose of purification by using zone melting, two main information can be extracted from this diagram:

- Dibenzothiophene does not seem to have a big impact on the solid-solid transition temperature of Phenanthrene.

- The Dibenzothiophene doping in Phenanthrene leads to partial solid solutions as for the other detected impurities $[9,10]$. These latter will lead to a rather poor segregation between solid and liquid phases during zone melting, and thus will lower the efficiency of the separation.

Even though a cooperative effect of the impurities cannot be ruled out, the study of heterogeneous equilibria between Phenanthrene and Dibenzothiophene lead to serious doubts on the efficiency of Phenanthrene purification by zone melting.

\section{Conclusions}

In order to reach ultra chemical purity of a thermally stable molecule, zone melting could be an efficient method. Nevertheless, this method implies also to characterize the main impurities of the desired component, and by extension to characterize the heterogeneous equilibria existing between these impurities and the desired molecule.

Commercial Phenanthrene appeared interesting (as a model molecule), mainly due to its remarkable stability at the molten state. The chemical analysis of the raw material revealed several impurities and Dibenzothiophene was the major one.

The heterogeneous equilibria between Phenanthrene and Dibenzothiophene (at atmospheric pressure) have thus been determined successfully by combination of structural and thermal analyses. The binary phase diagram is not fully clarified (one invariant in Dibenzothiophene rich-domain is still undefined), but this study has highlighted several solidsolution domains, and rationalized the impact of Dibenzothiophene on Phenanthrene solid-solid transition.

Further works are in progress to determine the heterogeneous equilibria between Phenanthrene and Fluorene (its second main impurity) particularly, and to estimate the impact of other fused-ring derivatives on Phenanthrene solid-solid transition. Then, experiments combining preparative chromatography [6] and zone melting will be tested in view to reach the highest possible purity of Phenanthrene.

\section{References}

1. G. Coquerel, Chem. Eng. Pro, 45 (2006)

2. J. Ulrich, H. Glade, Melt Crystallization: Fundamentals, Equipment and Applications (Shaker Verlag, Aachen, 2003)

3. W. G. Pfann, Trans. of the Am. Inst. of Mining Metal. Eng., 194 (1952)

4. J.L. Sola Cervera, P. Keil, A. König, Chem. Eng. Tech., 33, 5 (2010)

5. V. Petricek, I. Cisarova, L. Hummel, J. Kroupa, B. Brezina, Acta Cryst, B46 (1990)

6. J. McArdle, J.N. Sherwood, A.C. Damask, J. Cryst. Growth, 22, 3 (1974).

7. C.A. Peters, R.G. Luthy, Environ. Sci. Technol., 27 (1993)

8. G. Coquerel, Chem. Eng. Tech, 29, 2 (2006)

9. G. Bradley, J. K. Marsh, J. Chem. Soc., (1933)

10. M. Brandstatter-Kuhnert, H. WeiB, Mh. Chem, 88 (1957) 